\title{
A smoothed particle hydrodynamics study on modelling the flowability, passability and fill-ability of steel fibre suspended self-compacting concrete.
}

\author{
Sivakumar Kulasegaram* and Abdulkarim Mimoun* \\ * School of Engineering \\ Cardiff University \\ Newport Road, Cardiff CF24 3AA, United Kingdom \\ e-mail: KulasegaramS@cardiff.ac.uk
}

\begin{abstract}
Steel fibre (SF) has become an attractive alternative to the steel bar reinforcement in self-compacting concrete. To improve the efficiency and quality of self-compacting steel fibre reinforced concrete (SCSFRC), it is essential to fully understand the rheological properties of SCSFRC. Due to the nature of self-compacting concrete mix and widely varying properties of its constituents, it is hugely challenging to understand the rheological behaviour of the concrete mix. For this reason, its necessary to thoroughly comprehended fresh property by understanding its rheology. The quality control and accurate prediction of the SCSFRC rheology are crucial for the success of its production. The accurate prediction of the SCSFRC flowing, passing, and filling behaviour is not a simple task, particularly in the presence of heavy reinforcement, complex formwork shapes and large size of aggregate. In this regard, the complex formwork shapes and large size of aggregate can play an important role in the fibre orientation and distribution under the flow of fibre reinforced self-compacting concrete and can thus significantly influence mechanical behaviour of the material. Therefore, an indispensable and inexpensive approach offering considerable potential is the accurate numerical simulation of SCSFRC flow. This approach will deepen the understanding of the SCSFRC mix flow behaviour and evaluate its ability to meet the necessary self-compacting criteria of passing ability and segregation resistance.
\end{abstract}

A three-dimensional Lagrangian particle-based smooth particle hydrodynamics methodology is used here to simulate the flow characteristics of self-compacting concrete (SCC) mixes. This methodology has been used and proved to be an efficient and accurate in modelling the flow and monitoring the movement of large aggregates and/or short steel fibres of SCC in the slump cone flow, J-ring flow, and L-box test [1][2]. Further, computational simulations can also assist in proportioning SCC mixes, thus improving on the traditional trial and error SCSFRC mix design based on plastic viscosity and compressive strength. In this paper, a numerical method is developed to assess the orientation and distribution of steel fibres with various volume fractions in self-compacting concrete mixes during flow. The flow of self-compacting steel fibre reinforced concrete mixes with the range plastic viscosity of 30-70 Pas are simulated using three-dimensional Lagrangian SPH method to monitor the distribution of fibres and their orientation during the flow. The effectiveness and accuracy of the proposed computational technique are demonstrated via several numerical simulations.

Keywords: Self-compacting steel fibre reinforced concrete (SCSFRC), Fibre orientation and distribution, Smooth particle hydrodynamic, 3D simulation, Fibre orientation factor.

\section{REFERENCES}

[1] R. Deeb, S. Kulasegaram, and B. L. Karihaloo, '3D modelling of the flow of self-compacting concrete with or without steel fibres. Part I: slump flow test', Computational Particle Mechanics, vol. 1, no. 4, pp. $373-$ $389,2014$.

[2] R. D. S. K. B. L. Karihaloo, '3D modelling of the flow of self-compacting concrete with or without steel fibres . Part II : L-box test and the assessment of fibre reorientation during the flow', pp. 391-408, 2014.

[3] R. Deeb, A. Ghanbari, and B. L. Karihaloo, 'Development of self-compacting high and ultra high performance concretes with and without steel fibres', Cement and Concrete Composites, vol. 34, no. 2, pp. 185-190, 2012. 